\title{
Reduced Connexin26 in the Mature Cochlea Increases Susceptibility to Noise-Induced Hearing Loss in Mice
}

\author{
Xing-Xing Zhou ${ }^{1,+}{ }^{\dagger}$, Sen Chen ${ }^{1,+}{ }^{\dagger}$, Le Xie ${ }^{1}$, Yu-Zi Ji ${ }^{1}$, Xia Wu ${ }^{1}$, Wen-Wen Wang ${ }^{1}$, Qi Yang ${ }^{1}$, \\ Jin-Tao Yu ${ }^{1}$, Yu Sun ${ }^{1, *}, \mathrm{Xi} \mathrm{Lin}^{2}$ and Wei-Jia Kong ${ }^{1,3, *}$ \\ 1 Department of Otorhinolaryngology, Union Hospital, Tongji Medical College, \\ Huazhong University of Science and Technology, Jiefang Avenue 1277, Wuhan 430022, China; \\ star1028@126.com (X.-X.Z.); cs88030067@sina.com (S.C.); leoxie5842@gmail.com (L.X.); \\ jiyuzi1987@sina.com (Y.-Z.J.); wuxia027@163.com (X.W.); wangwenwen@hust.edu.cn (W.-W.W.); \\ yangqitj@sina.com (Q.Y.); yujintaoly@163.com (J.-T.Y.) \\ 2 Department of Otolaryngology Head and Neck Surgery, Emory University School of Medicine, \\ 615 Michael Street, Whitehead Bldg Rm\#543, Atlanta, GA 30322, USA; xlin2@emory.edu \\ 3 Institute of Otorhinolaryngology, Tongji Medical College, Huazhong University of Science and Technology, \\ Wuhan 430022, China \\ * Correspondence: sunyu@hust.edu.cn; (Y.S.); entwjkong@hust.edu.cn (W.-J.K.); Tel.: +86-27-8535-1632 (Y.S.); \\ +86-27-8535-1706 (W.-J.K.); Fax: +86-27-8577-6343 (Y.S. \& W.-J.K.) \\ + These authors contributed equally to this work.
}

Academic Editor: Nicholas Delihas

Received: 20 January 2016; Accepted: 22 February 2016; Published: 26 February 2016

\begin{abstract}
Connexin26 (Cx26, encoded by GJB2) mutations are the most common cause of non-syndromic deafness. GJB2 is thought to be involved in noise-induced hearing loss (NIHL). However, the role of Cx26 in NIHL is still obscure. To explore the association between Cx26 and NIHL, we established a Cx26 knockdown (KD) mouse model by conditional knockdown of Cx26 at postnatal day 18 (P18), and then we observed the auditory threshold and morphologic changes in these mice with or without noise exposure. The Cx26 KD mice did not exhibit substantial hearing loss and hair cell degeneration, while the $\mathrm{C} \times 26 \mathrm{KD}$ mice with acoustic trauma experienced higher hearing loss than simple noise exposure siblings and nearly had no recovery. Additionally, extensive outer hair cell loss and more severe destruction of the basal organ of Corti were observed in Cx26 KD mice after noise exposure. These data indicate that reduced Cx26 expression in the mature mouse cochlea may increase susceptibility to noise-induced hearing loss and facilitate the cell degeneration in the organ of Corti.
\end{abstract}

Keywords: Connexin26; GJB2; noise-induced hearing loss

\section{Introduction}

GJB2 mutations are the most common causes of non-syndromic deafness and more than 100 GJB2 mutations are linked with hearing impairment. Gap junctions (GJs), which facilitate the exchange of ions, small molecules and second messengers, are arrays of intercellular channels that are composed of connexin protein subunits [1-4]. In the mammalian inner ear, connexin26 (Cx26), which is encoded by GJB2, is mainly assembled with Cx30 to form heteromeric $\mathrm{C} \times 26 / \mathrm{C} \times 30$ gap junctions in supporting cells and fibrocytes $[4,5]$. Cx26 is thought to participate in potassium circulation, calcium propagation or endogenous signal communications in the cochlea.

Due to the vital role of Cx26 in cochlear physiology, numerous studies have explored the correlation between the genetic basis of GJB2 mutations/polymorphisms and other types of hearing 
loss, such as noise-induced hearing loss (NIHL); however, the results have been contradictory. The GJB2 35delG mutation is the most common mutation detected in the GJB2 gene in the Caucasian population [6,7]. According to previous studies, the $35 \mathrm{delG}$ mutation can lead to a frameshift and premature termination of protein translation. Therefore, persons homozygous for the 35delG mutation may suffer mild to profound hearing loss, but carriers may have normal hearing [8,9]. In 2004, an investigation was conducted among Swedish workers to determine whether GJB2 35delG mutation carriers had high susceptibility to NIHL, and the results demonstrated that there was no significant correlation between the GJB2 35delG mutation and NIHL [10]. Similar conclusions were drawn in Polish and Brazilian population [11,12]. However, another analysis of single nucleotide polymorphisms (SNPs) indicated that the GJB2 gene may be significantly associated with NIHL. In this study, 119 matched pairs of Polish workers who were sensitive or resistant to noise were included, and the odds ratio (95\% CI) of the GJB2 SNP (rs3751385) was discovered to be 2.064 [13]. Recently, another study on Chinese NIHL workers suggested that gene-gene interaction among GJB2 SNP (rs137852540), SOD2 and CAT might account for NIHL development; however, when analyzed independently, the single GJB2 SNP (rs137852540) did not increase the risks of NIHL [14].

To explore the association between GJB2 and NIHL, more objective animal models should be established. To avoid having to breed different mutation models, the conditional gene knockout mouse is an ideal and convenient tool that may be useful for hearing research. The loss of Cx26 in the cochlea may partially imitate the loss of function caused by corresponding mutations. However, previous Cx26 null mice exhibited congenital severe hearing loss after birth when Cx26 was reduced during embryonic periods. These mice were good models for congenital non-syndromic deafness but were not appropriate for noise exposure [15-17]. Our group and Zhao et al. [18-20] had successfully induced Cx26 knocked down (KD) in mice at postnatal day 10 to12 (P10 to P12), in which hearing impairment was discovered to be mild. Subsequently, a series of deletion time points before or after the onset of hearing (about P14) were systematically investigated in the similar model. The results suggested that the hearing might not be affected up to one month following deletion of Cx26 that occurs after P16 [21]. Therefore, we predict that $\mathrm{C} \times 26$ reduction at more mature stages will provide a relative safe time for noise exposure research.

To further study the correlation between Cx26 and NIHL, herein, cochlear Cx26 was reduced at postnatal day 18 (P18) in animals that were exposed to discontinuous white noise. Our data suggests that normal hearing is maintained in mice when Cx26 is reduced in mature cochlea; however, loss of Cx26 exacerbates hearing loss and the cochlear cell degeneration that occurs after acoustic trauma.

\section{Results}

\subsection{Connexin26 Deletion in Conditional Cx26 Knocked down Mice}

In this study, Cx26 was successfully knocked down in mice cochleae at P18. Compared to the control group at $\mathrm{P} 30$ (Figure 1A,B), western blots indicated that the $\mathrm{Cx} 26$ protein in $\mathrm{KD}$, noise and KN groups were $66.0 \% \pm 11.5 \%(p=0.014), 94.8 \% \pm 9.9 \%(p>0.05)$ and $71.8 \% \pm 5.7 \%(p=0.031)$, respectively. As shown in Figure 1C, Cx26 staining (red) was detected in the organ of Corti, lateral wall and spiral limbus in control and noise groups at P30, and the labeling was partly absent in the organ of Corti and spiral ligament in KD and KN group. Following investigation of flattened cochlear preparations, the Cx26 staining (red) was restricted to the circumference of the Pillar and Deiter cells in the control and noise group. In contrast, there was significantly reduced Cx26 staining of these cells in the KD and KN groups (Figure 1D). 
A

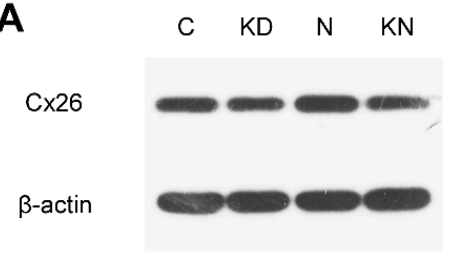

B

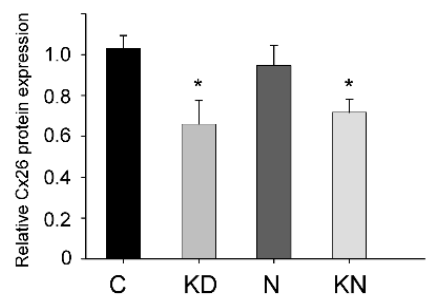

D

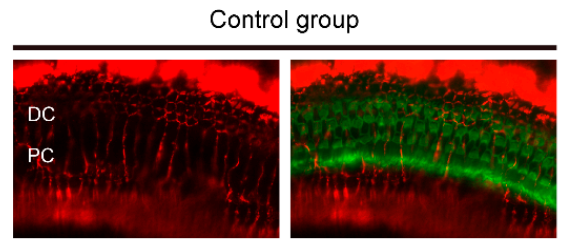

Noise group

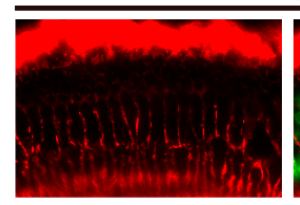

C

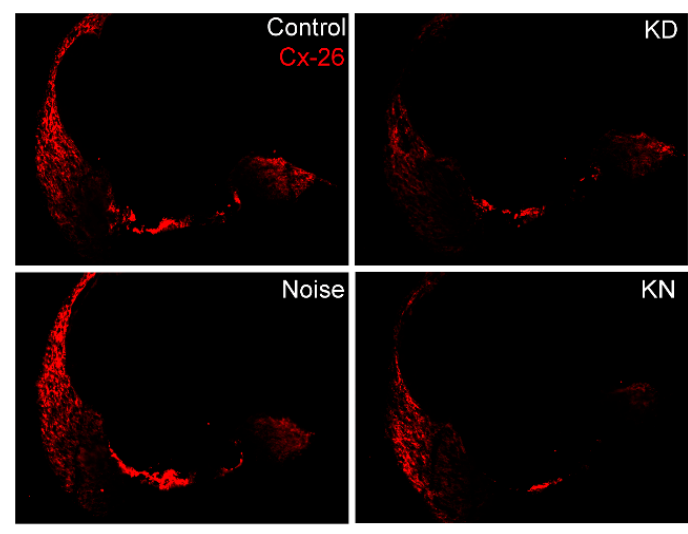

KD group

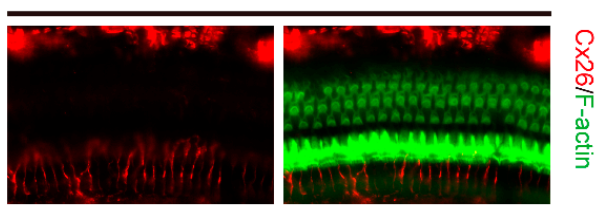

$\mathrm{KN}$ group

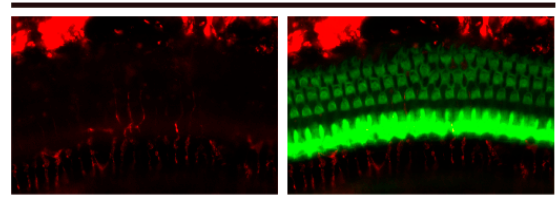

Figure 1. Connexin26 deletion in conditional connexin26 (Cx26) Knockdown (KD) mice after noise exposure. Summary of Cx26 expression in control and experimental groups. (A,B) Western blot and histogram detecting $\mathrm{Cx} 26$ in the cochleae of control, KD, noise and knockdown+noise groups (KN groups) at P30 ( $n=4$ in each group); (C) Immunolabeling of Cx26 (red) in the cochlear sections of control and different experimental groups at P30; (D) Immunolabeling of Cx26 (red) and phalloidin (green) in flattened cochlear preparations of control and experimental groups at P30. There was an obvious Cx26 reduction in Deiter and Pillar cells of KD and KN mouse groups. Abbreviations: PC: Pillar cell; DC: Deiter cell. ${ }^{*} p<0.05$ when compared with the control group.

\subsection{Hearing Thresholds Shift after Cx26 Reduction and Noise Exposure}

Cx26 reduction could potentially exacerbate hearing loss in the $\mathrm{KN}$ group. In previous studies, knocking down Cx26 in mature cochlea (after P16) could not lead to a rapid and notable deafness. Additionally, the mice showed a stable hearing one month following the knockdown, providing a prerequisite for noise exposure in the present study. In the present, there were no substantial hearing differences between control and KD group at P30 and P45 (Figure 2A,B). At P30, the hearing thresholds in the noise group at $8-48 \mathrm{kHz}$ were $75.0 \pm 2.99,75.8 \pm 2.1,77.25 \pm 2.15,84.25 \pm 1.80$ and $89.5 \pm 1.71$ $\mathrm{dB}$ SPL, respectively. The ABR thresholds in the KN group were $82.9 \pm 2.13,80.2 \pm 2.64,82.7 \pm 2.59$, $85.2 \pm 2.19$ and $88.5 \pm 1.08 \mathrm{~dB}$ SPL, respectively. After two weeks, the auditory threshold at low frequency showed partial recovery in noise group (Figure 2B); however, recovery was not found in $\mathrm{KN}$ group. At $\mathrm{P} 45$, the thresholds at $8-48 \mathrm{kHz}$ in noise group were $67.5 \pm 2.94,70.0 \pm 2.34,72.1 \pm 2.84$, $78.9 \pm 3.16$ and $88.6 \pm 1.37 \mathrm{~dB}$ SPL, respectively. However, the thresholds in the KN group were $80.5 \pm 2.22,78.0 \pm 2.40,78.4 \pm 3.40,86.4 \pm 1.69$ and $90.0 \pm 0.00 \mathrm{~dB}$ SPL, respectively. The differences between noise and KN group were significant at 8,16 and $32 \mathrm{kHz}(p<0.01$, student $t$-test). 
A

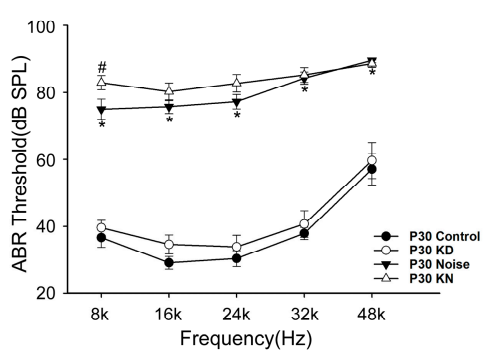

B

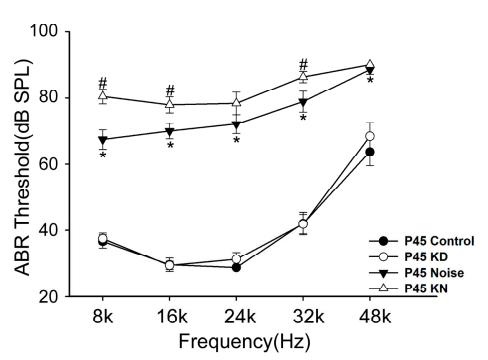

Figure 2. Hearing thresholds shift after $\mathrm{Cx} 26$ reduction and noise exposure. Auditory thresholds were measured in control, KD, noise and KN group at P30 (A) and P45 (B). * Significantly different from

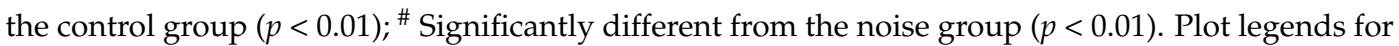
different groups are given in the panel.

\subsection{Cx26 Reduction Exacerbates Hair Cell Loss in the Knockdown + Noise Groups (KN Groups)}

At P30 or P45, no substantial hair cell (HC) loss was observed in control and KD groups (Figure 3A,B). However, obvious outer hair cell $(\mathrm{OHC})$ loss was observed in the basal region in noise and KD groups. At P30, 4\%-30\% of outer hair cell loss was found in the cochlear middle to basal turn of the noise group (Figure 3C), and the stereocilium and cuticular plate (phalloidin staining, red) were degenerated in the corresponding region. The outer hair cell loss in the $\mathrm{KN}$ group was more severe than that in the noise group. The degeneration of $\mathrm{OHCs}$ was scattered in middle turn and some focal lesions could be seen in the basal turn (Figure 3A,C). At P45, basal OHC loss in noise and KN groups was exacerbated. Hair cell counting indicated that approximately $10.0 \%-58.2 \%$ of the OHCs were lost in the cochlear middle to basal turn of the KD group (Figure 3B,D).
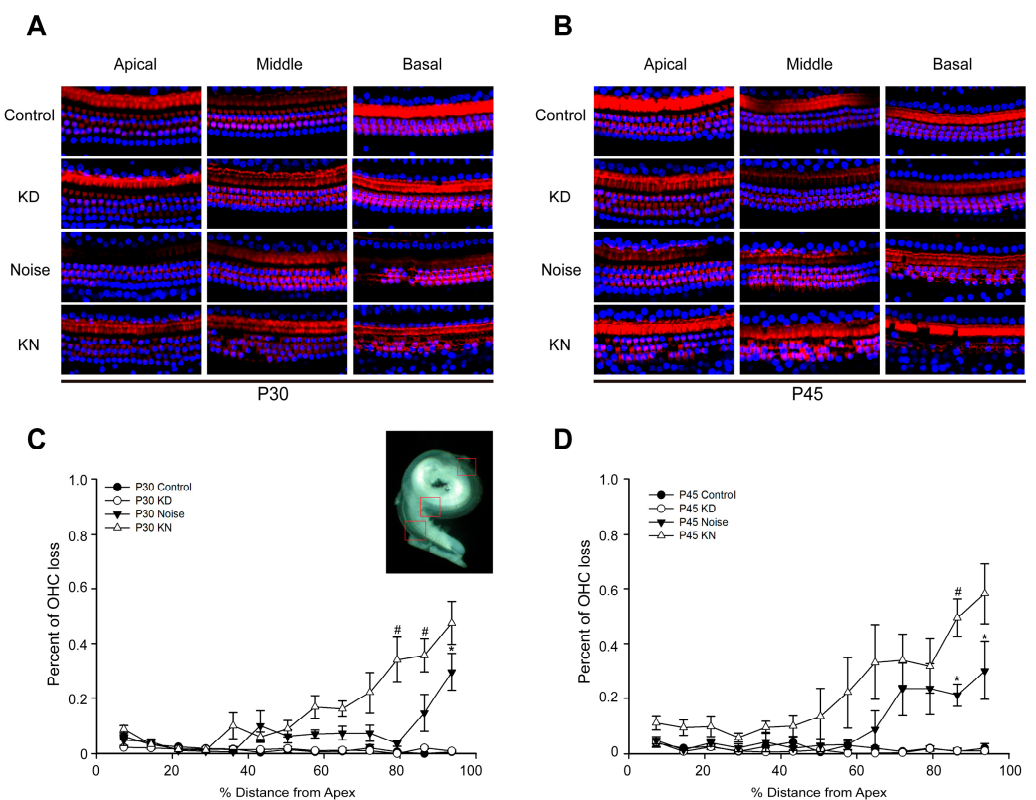

Figure 3. Hair cell loss patterns in control, KD, noise and KN groups. Patterns and time courses of $\mathrm{OHC}$ loss in control and experimental groups $(n=3-4$ in each group). Panels $(\mathbf{A}, \mathbf{B})$ show the examples of the HC nucleus (blue) and F-actin (red) in control, KD, noise and KN groups; Three rows of OHCs are at the bottom; Panels (C,D) show quantifications of OHC loss at specific cochlear locations in control and different experimental groups. The inset in panel $\mathrm{C}$ shows a dissected surface preparation and the red frames represent different check points. ${ }^{*}$ Significantly different from the control group $(p<0.05)$; " Significantly different from the noise group $(p<0.05)$. Plot legends for different groups are given in the panels. 


\subsection{Cell Degeneration Pattern after Cx26 Reduction and Noise Exposure}

Resin sections were stained for morphological observation at P45 (Figure 4). The panel A and $B$ show a full view of a cochlear section in the noise and KD group, respectively (Figure $4 A, B$ ). The basal turns in the four groups were magnified in the right panels. Neither cell degeneration nor deformity were obvious in the organ of Corti (OC), stria vascularis (SV) or spiral ligament of control and KD groups (Figure 4C,F). The tunnel of Corti (TC) and the Nuel's space were well developed in control and KD group (Figure 4D,G). In contrast, OHC loss was obvious with a general preservation of surrounding supporting cells in the basal turn of noise group (Figure 4J). Further, focal collapse of basal OC (Figure 4M, black arrow) in KD group was observed and the nerve fibers (Figure 4M, black arrowhead) were missing in some sections; however, the OC was generally preserved in the middle and apical turn (Figure S1). Consequently, the spiral ganglion neuron degeneration in corresponding region was observed (Figure $4 \mathrm{~N}$ ). Some enlarged intercellular spaces were observed in the spiral ligament of the KN group (Figure 4B); however, significant differences were not observed in stria vascularis (SV) when comparing between the four groups using an optical microscope.
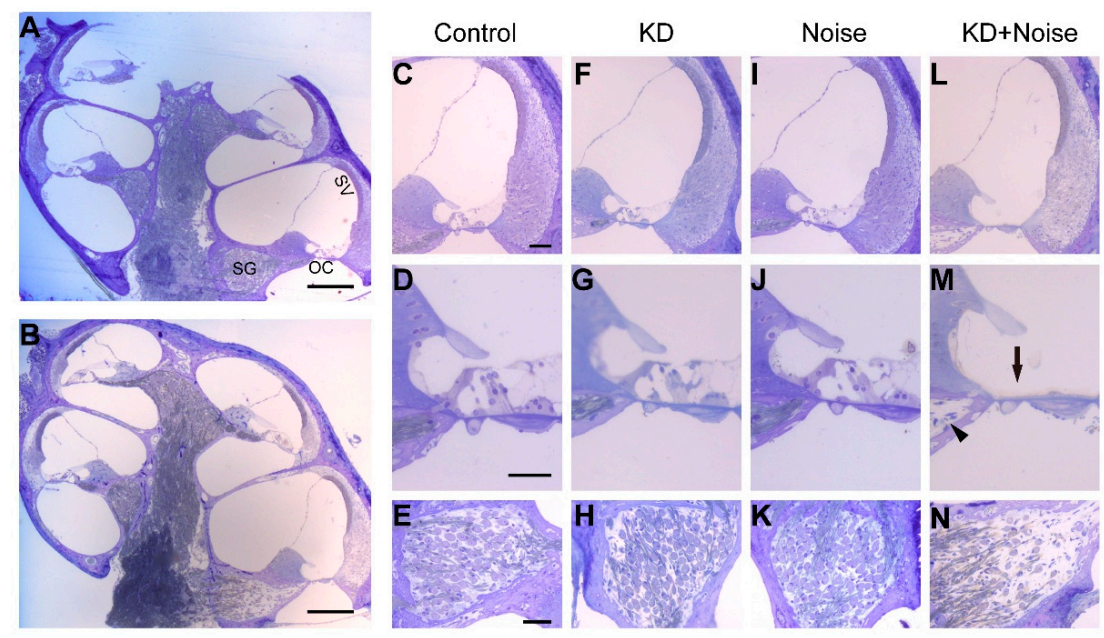

Figure 4. Cochlear morphology of the basal turn in control, KD, noise and KN groups. A full view of a cochlea obtained from noise (A) and KN groups (B); Panels C, F, I and L show the morphology of the cochleae at the basal turn in control and experimental groups; Panels D, G, J and $\mathbf{M}$ show the morphology of the magnified OC in panels C, F, I and L, respectively; Panels E, H, K and N show the SGN at the basal turn in the different groups. Abbreviations: SV: stria vascularis; OC: organ of Corti; SG: spiral ganglia. The scale in panel represents $200 \mu \mathrm{m}$, and scales in panel C, D and E represent approximately $40 \mu \mathrm{m}$.

\subsection{Ultrastructural Changes after Cx26 Reduction and Noise Exposure}

The OC and SV were observed at P45 by a transmission electron microscope. As shown in Figure 5A,B, the TC and Nuel's space were well developed in the control and KD group. The Pillar cells and Deiter cells were intact and no significant mitochondria pathological lesions were found in these two groups. However, in the noise group, outer hair cell degeneration was distinct and some Deiter cells were transitioning into tall columnar cells that support the cuticular plate (Figure 5C, arrow). Some of the inner hair cells in the noise group displayed a shrunken nucleus and a dark cytoplasm with different vacuoles (Figure 5C, arrowhead). As shown in optical microscope, the basal OC from some sections was totally collapsed in the KN group. Massive loss of hair cells and supporting cells occurred in the KN group at P45 (Figure 5D). 


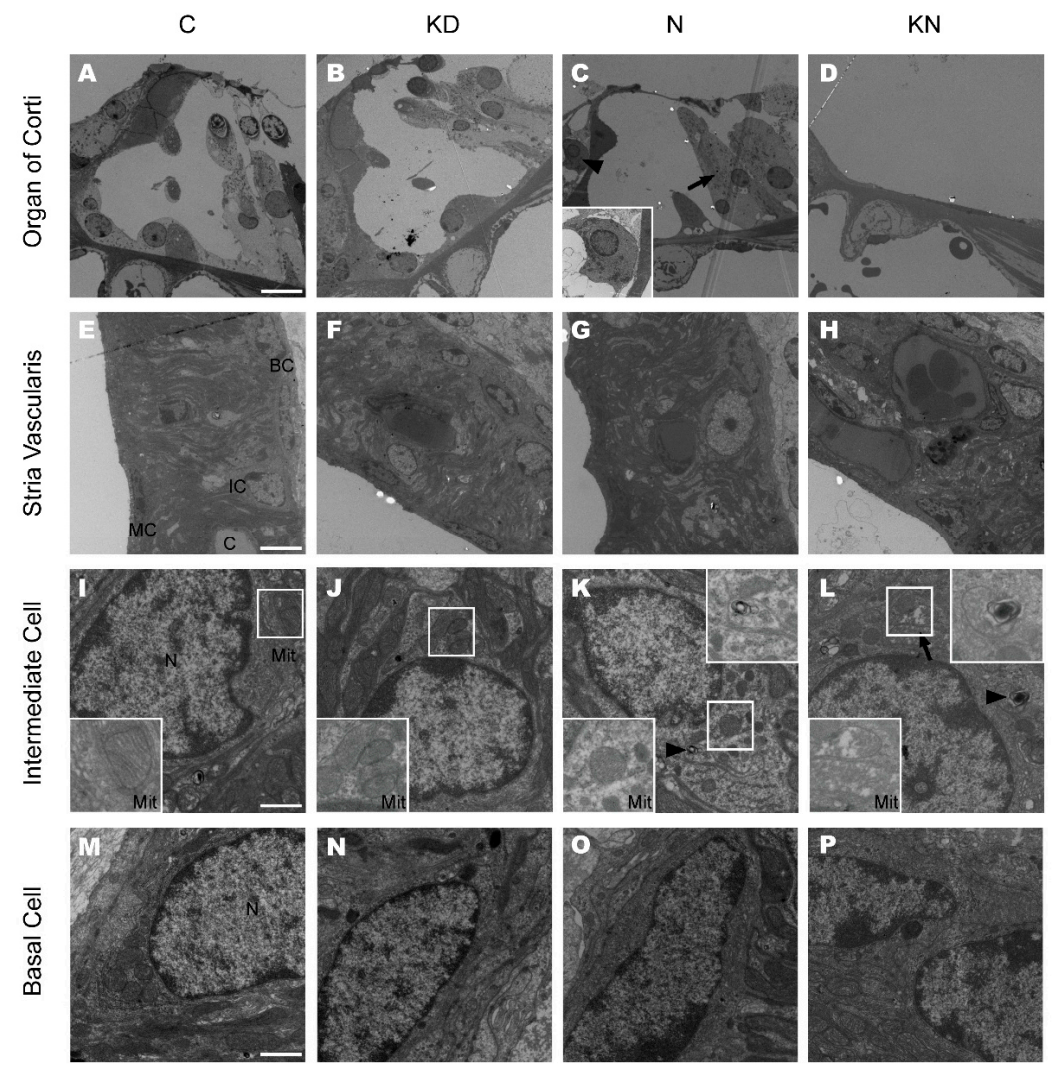

Figure 5. Ultrastructure of cochleae at the basal turn in control, KD, noise and KN groups. The ultrastructure of the basal turn of the cochlea was observed in control and different experimental groups at P45 ( $n=3$ in each group). Panels A, B, C and D show the basal OC in control, KD, noise and $\mathrm{KN}$ groups. Distinct OHC loss was observed in noise group (C) and the basal OC was collapsed in KN group (D). The inset (panel C) in the left bottom show the inner hair cell; Panels E, F, G and $\mathbf{H}$ show the SV at the basal turn in different groups; Panels I, J, K and L show the ultrastructure of IC at the basal turn in control and experimental groups. The insets (panels I, J, K and $\mathbf{L}$ ) on the left bottom show mitochondria and the myelinbody was magnified in the upper right boxes (Panel $\mathbf{K}$ and $\mathbf{L}$ ). Panels $\mathbf{M}, \mathbf{N}, \mathbf{O}$ and $\mathbf{P}$ show the ultrastructure of $\mathrm{BC}$ in stria vascularis. Abbreviations: SV: striavascularis; OC: organ of Corti; IC: intermediate cell; BC: basal cell; MC: marginal cell; C: capillary. The scales in panel A, E, I and $\mathbf{M}$ represent 10, 5, 1 and $1 \mu \mathrm{m}$, respectively. The arrow in $\mathbf{L}$ is pointing out a mitochondria and the arrowhead indicates a myelinbody.

The structure of the SV did not display significant differences among the four groups. Additionally, the three-layers structure was well arranged and the strial capillaries were opened with normal vascular endothelial cells in the four groups (Figure 5E-H). Marginal cells (MC) extending long processes filled with mitochondria were found in the SV. A few swollen mitochondria with disrupted cristae could be observed in the processes of $\mathrm{MC}$ in the $\mathrm{KN}$ group. A majority of mitochondria with distinct cristae were observed in perinuclear cytosol of intermediate cells (IC) from control, KD and noise group (Figure $5 \mathrm{I}, \mathrm{J}, \mathrm{K}$ ). In the noise group, the myelin body was seen occasionally in intermediate cell (Figure 5K arrowhead). In KN group, some mitochondria with disrupted cristae could be found and a few myelin bodies still existed (Figure 5L). No obvious ultrastructural lesions were found in basal cells of the four groups (Figure 5M-P).

\section{Discussions}

Cx26 mutations are the most common cause for non-syndromic deafness [22]. Various deafness mechanisms and explanations have been proposed by studying Cx26 null mice. In embryonic 
Cx26 null mice, a majority of hair cell loss in the middle and basal turn and SG degeneration in corresponding regions have been observed at P30 and are thought to cause severe congenital deafness $[16,23]$. In comparison with other transgenic mouse strains, OC deformity with a closed tunnel of Corti have become the focus and have provided new evidence in recent studies $[15,17]$. By use of conditional knockout mice, Cx26 could be deliberately knocked down at different time points. Developmental disorders of the mouse cochlea have been elaborately investigated, and the results indicate that reducing Cx26 at embryonic periods or during early postnatal days could arrest TC development $[18,24]$. More importantly, hearing loss was alleviated and led to later-onset deafness when the knocking down time points came at later days after birth (P10-P12) without obvious developmental disorders $[18,20,21]$. Although Cx26 played an indispensable role in cochlear postnatal development, little evidence on Cx26 functions in mature cochlea was found. A previous mechanism involving the endocochlear potential (EP) or propagation of calcium still could not explain that reduced widespread Cx26 in later postnatal development stages (P10-P12) only leads to mild hearing loss $[18,20,25,26]$.

Mice cochleae is born immature and the normal hearing matures at P16-P18 [27,28]. Zhao's group has observed significant hearing loss at P35-P60 by deleting Cx26 only in outer Pillar and Deiter cell regions at E18 [29]. In this study, we reduced the cochlear Cx26 at P18 to avoid the influence on the cochlear development and a significant Cx26 reduction could be ensured in OC region. Compared with control siblings, there were no significant differences in the ABR thresholds, hair cell number or ultrastructure in KD mice at P45. Similar results were observed by Lin's group that the mice deleting Cx26 at P16 and P30 showed a normal hearing in the following month [21]. These results indicate that a small quantity of Cx26 can maintain the cochlear physiology and the Cx26 expression in normal mature cochlea may have certain reserve capacity. However, the dose-effect relationship between Cx26 levels and the degree of hearing impairment and cell degeneration in mature cochleae needs further study.

Noise is one of the most prevalent ototoxic stresses and causes different patterns of hearing loss that are associated with cellular injury in accordance with the noise intensity and exposure time [30,31]. One hypothesis is that reduced Cx26 during mature stages may be a risk factor for specific types of deafness, especially noise-induce hearing loss. In our observations, a $13 \mathrm{~dB}$ gap was found at $8 \mathrm{kHz}$ between the noise and $\mathrm{KN}$ group at P45. Moreover, reducing Cx26 resulted in greater OHC loss and the OC collapse, suggesting that the Cx26 loss exacerbates acoustic trauma and cell degeneration. It was reported that the outer hair cells in the basal turn were the most vulnerable targets for noise exposure and the Pillar and Deiter cells had more resistant ability for high intensity noise [30,32-34]. In our study, the OHC loss in noise group was the major pathological change and it confirmed the previous observations. However, loss of supporting cell in the KN group indicated that reduced Cx26 may induce both $\mathrm{OHC}$ and supporting cell degeneration during acoustic trauma. It has been shown that supporting cells may played a decisive role in SGN survival [35], potentially explaining why there was an obvious SGN degeneration in the basal turn of the KN group. As a result of Cx26 reduction and noise exposure in mature cochlea, our results provide direct evidence to support the involvement of Cx26 in NIHL. Considering the different protein functional defects that are caused by the various GJB2 mutation genotypes, the human GJB2 gene mutations/SNPs may have more complicated effects on NIHL than those observed herein. A transgenic mouse model, such as a mouse carrying the 35delG mutation, should be established for further investigation.

It is possible that the severe cell degeneration may be induced by the synergistic effects of decreased Cx26 and noise exposure in the $\mathrm{KN}$ group; however, the mechanisms still need to be investigated. It is thought that the gap junction can connect the adjacent supporting cells and that as a result, the energetic metabolites could be transmitted through it. In embryonic Cx26 null mice, Claudius cell degeneration was first found at P8. Shortly afterwards, dramatic OHC and surrounding supporting cell death were observed at approximately P13 [17,36]. Glucose imaging research has suggested that the glucose analogue distribution is depressed by uncoupling the gap junction in spiral 
limbus and spiral ligament $[37,38]$. Similarly, Lin's group has found that glucose analogue among cochlear Claudius cells was severely reduced in Cx30 null mice [39]. Together, these results suggest that there may be aberrant energy metabolism in the mature supporting cells that lack the Cx26. Additionally, the noise exposure could also induce energy depletion in hair cells and supporting cells. The intracellular ATP concentrations in cochlear extracts have been shown to decrease immediately after noise exposure, and p-AMPK $\alpha$, an energy sensor activated by an up-regulation in the AMP / ATP ratio, has also been shown to increase in the sensory hair cells of mice $1 \mathrm{~h}$ after traumatic noise exposure[40]. Further, Kiyokazu Ogita et al. [41] have observed that the p-AMPK $\alpha$ is elevated in Pillar cells and lateral wall structures after noise exposures of at least $110 \mathrm{~dB}$. These data indicated that the combined effects of reduced Cx26 and noise exposure may induce excessive energy depletion and thereby result in cell degeneration. Moreover, in previous studies, it have been suggested that the generation of reactive oxygen species (ROS) may be an underlying cause of NIHL [42,43]. In cultured endothelial cells, localized oxidative insults have been shown to propagate between cells through gap junction (Cx43) inter-cellular communication [44]. In another study, lack of Cx43 or blockage of the Cx43 channel could increase ROS-induced astrocytic death [45]. In cochleae, the loss of Cx26 in the OC may cause dysfunction of the heterogenic $\mathrm{Cx} 26 / \mathrm{C} \times 30$ gap junctions and obstructed the ROS propagation. Excessive ROS generation induced by the combined effects of noise exposure and Cx26 deletion may be the cause of severe cell death.

\section{Materials and Methods}

\subsection{Generation of the Connexin26 (Cx26) Conditional Knockdown (KD) Mouse Model and Genotyping}

Cx26 ${ }^{\text {loxP/loxP }}$ mice and Rosa26CreER ${ }^{\mathrm{T}}$ mice were kindly provided by $\mathrm{Xi}$ Lin at Emory University. Mice were raised in the specific-pathogen free (SPF) Experimental Animal Centre of Huazhong University of Science and Technology. As reported previously, Cx26 $6^{\mathrm{loxP} / \mathrm{loxP}}$ mice were crossed with Rosa26CreER ${ }^{\mathrm{T}}$ mice to generated Cx26 $6^{\text {loxP/loxP}}$; Rosa26CreER ${ }^{\mathrm{T}}$ mice [22]. The Cx26 in these mice could be deleted by tamoxifen induced Cre recombinase activation. Mouse genotyping was performed by PCR amplification of tail genomic DNA. The primer pairs for Cx26 floxed allele and Cre transgene were as follows: Cx26F: 5'-ACAGAAATGTGTTGGTGATGG-3' and Cx26R: 5'-CTTTCCAATGCTGGTGGAGTG-3'; CreF: 5'-AGCTAAACATGCTTCATCGTCG GTC-3'and CreR: 5'-TATCCAGGTTACGGATATAGTTCATG-3'. In this study, all mice were injected tamoxifen (1.2 mg/10 g, T5648-1G, Sigma-Aldrich, St. Louis, MO, USA) intraperitoneally at P18. Animal experiments in this study followed protocols approved by the Institutional Animal Care and Use Committee at Tongji Medical College, Huazhong University of Science and Technology (Permit No. S429).

\subsection{Animal Treatment and Noise Exposure Procedure}

Mice were divided into four groups: control group, knockdown group (KD group), noise group and knockdown + noise group (KN group). Tamoxifen induced Cx26loxP/loxP Rosa26CreER ${ }^{\mathrm{T}}$ mice were used for $\mathrm{KD}$ and $\mathrm{KN}$ group, while the littermates lacking Cre were used for the control and noise group.

Mice in noise group or KN group were exposed to white noise at $110 \mathrm{~dB}$ SPL (sound pressure level) in a soundproof chamber. The noise exposure was imposed on mice at P25 and sustained $8 \mathrm{~h}$ per day for five consecutive days. A loudspeaker (TSM-102, Chanstek Audio Inc., Foshan, China) suspended $20 \mathrm{~cm}$ above the mouse cage was driven by a power amplifier (TMA-101, Tamo, HuaTai electronic Co., Hangzhou, China) that was fed from a computer. A PlayOne software was used to manipulate the exposure procedure. The mouse cage $(290 \times 190 \times 225 \mathrm{~mm})$ is made of polycarbonate with an iron railing on the roof and no more than 5 mice were loaded at once. Sound levels was calibrated by a sound level meter on the roof of the cage (TES1350A, TES Electrical Electronic Corp., Guangzhou, China) with about $2 \mathrm{~dB}$ SPL attenuation in four corners. 


\subsection{Auditory Brainstem Recordings}

Auditory brainstem response was performed at P30 and P45. Mice ( $n=6-12$ in each group) were anesthetized with ketamine (120 mg/kg i.p.) and chlorpromazine $(20 \mathrm{mg} / \mathrm{kg}$, i.p.), and body temperature was maintained with a heating pad in a soundproof chamber. Recording electrode was placed at the vertex, and a reference electrode was inserted at tested ear with a ground electrode at the contralateral ear. Tone burst stimuli were generated and responds were recorded by the Tucker-Davis Technologies System (RZ6, Tucker-Davis Tech., Alachua, FL, USA) at frequencies of 8, 16, 24, 32 and $48 \mathrm{kHz}$. A loudspeaker (MF-1, Tucker-Davis Tech.) connected to the system was placed $10 \mathrm{~cm}$ away from the tested ear with another ear plugged. Responses were averaged 1024 times and recorded in decreasing $10 \mathrm{~dB}$ steps, then narrowing to $5 \mathrm{~dB}$ step near the threshold. The lowest sound level that elicited a repeatable wave was considered as the threshold.

\subsection{Protein Extraction and Western Blot Analysis}

The Cx26 protein levels ( $n=4$ in each group) were determined by western blot analysis. Cochleae were carefully dissected in ice cold PBS, and samples of membranous labyrinth were proceed in RIPA lysis buffer (P0013B, Beyotime Biotechnology, Haimen, China). A BCA Protein Assay Kit (P0012S, Beyotime) was used to determine the protein concentrations.

Proteins were separated by electrophoresis on $12 \%$ sodium dodecyl sulphate (SDS) polyacrylamide gels and then transferred to polyvinylidenedifluoride (PVDF) membranes. The membranes were blocked in TBST containing 5\% milk for $1 \mathrm{~h}$ and then incubated overnight with rabbit polyclonal antibodies against Cx26 (1:1000, 710500, Invitrogen, Thermo Fisher Scientific Inc., Waltham, MA, USA) or rabbit polyclonal antibodies against $\beta$-actin (1:1000, 04-1116, Millipore, Merck Millipore Corporation, Darmstadt, Germany). Immunodetection was accomplished with horseradish peroxidase-conjugated goat anti-rabbit antibody and chemiluminescence with an ECL reaction kit (P0018, Beyotime). Bands were recorded by exposure on medical film and were analyzed by normalizing to the corresponding controls using Quantity One 4.6.2 Software (Bio-Rad Laboratories Inc., Alfred Nobel Drive Hercules, CA, USA).

\subsection{Cochlear Tissue Preparation and Immunofluorescent Labeling}

The temporal bones were harvested and dissected at P30 and kept in 4\% paraformaldehyde in PBS for $1 \mathrm{~h}$ at room temperature. After decalcification with disodium EDTA for 48-60 $\mathrm{h}$, the cochleae were dehydrated with $20 \%$ and $30 \%$ sucrose for $1.5 \mathrm{~h}$ respectively and embedded in OCT. Modiolar sections with a thickness of $10 \mu \mathrm{m}$ were cut for subsequent procedure. For flattened cochlear preparations, the apical basilar membrane was carefully dissected from fresh cochleae in $4 \%$ paraformaldehyde, and washed in 0.01 M PBS. The sections or flattened cochlear preparations were incubated and permeabilized in a blocking solution (10\% donkey serum and $0.3 \%$ Trion X-100) for $1 \mathrm{~h}$ at room temperature. $\mathrm{Cx} 26$ protein was recognized by overnight incubation at $4{ }^{\circ} \mathrm{C}$ with a polyclonal rabbit anti-Cx26 antibodies (1:200, Invitrogen) diluted in 0.01 M PBS. After washing with PBST (0.01 M PBS with $0.1 \%$ Tween-20), samples were stained by a fluorescently tagged secondary antibody (1:200, ANT030, Antegen Biotechnology Inc., Wuhan, China) for $1 \mathrm{~h}$ and DAPI (C1005, Beyotime Biotechnology, Haimen, China) for $5 \mathrm{~min}$ at room temperature, respectively. For flattened cochlear preparation immunostaining, the $F$-actin was additionally stained by phalloidin $(0.005 \mathrm{mg} / \mathrm{mL}, \mathrm{P} 5282$, Sigma, Sigma-Aldrich Corporation, St. Louis, MO, USA) for $30 \mathrm{~min}$ at room temperature. Images were captured on fluorescence microscope (DM2500, Leica, Leica Microsystems, Wetzlar, Germany). Images were post-processed with Adobe Photoshop software (Version 10.0, Adobe Systems Inc., San Jose, CA, USA). 


\subsection{Quantification of Cochlear Hair Cells}

The flattened cochlear preparation ( $n=3-4$ in each group) dissected from decalcifying cochleae were separated into 4 portions. After permeabilization with $0.3 \%$ Triton X-100 in 0.01 MPBS for 5 min, the samples were stained by phalloidin $(0.005 \mathrm{mg} / \mathrm{mL}$, P1951, Sigma) for $30 \mathrm{~min}$ at room temperature. Nuclei were stained with DAPI for $5 \mathrm{~min}$, and then the flattened preparations were mounted on glass slides. Images were taken with a laser confocal microscope (Nikon, Tokyo, Japan). To get the cochleograms, about 2100 outer hair cells in each sample were counted in 13 consecutive fields from the apex to the basal portion. The last part of the basilar membrane was anfractuous and hard to obtain, so the counted parts covered nearly 90 percents of the whole basilar membrane.

\subsection{Resin Sections and Transmission Electron Microscopy}

The cochleae ( $n=3$ in each group) were opened in the apex and flushed using $2 \%$ PFA with $2 \%$ glutaraldehyde in $0.1 \mathrm{M} \mathrm{PB}$ buffer. After decalcification, the samples were post-fixed for one hour in $1 \%$ osmium tetroxide and then dehydrated through a graded ethanol series. After embedding using an Epon $812 \mathrm{kit}$, cochleae were sectioned ( $2 \mu \mathrm{m}$ in thickness) and stained with toluidine blue for light microscope observation. The ultrathin sections $(80 \mathrm{~nm}$ in thickness) were stained with uranyl acetate and lead citrate for electron microscopy examination (H7100, Hitachi, Tokyo, Japan).

\subsection{Statistical Analysis}

All data were presented as mean \pm s.e.m. and plotted by SigmaPlot (Version 12.5, Systat Software, Inc., San Jose, CA, USA). One-way ANOVA with a LSD correction or $t$-test were performed by SPSS software (version 19, IBM SPSS Statistics, New York, NY, USA) for statistical analysis. $p<0.05$ was considered to be statistically significant.

\section{Conclusions}

In conclusion, the present study demonstrates that mature cochleae (P18) with partial loss of Cx26 did not exhibit auditory dysfunction and cell degeneration in a certain period. However, reduced Cx26 in mature cochleae in mice increased susceptibility to noise-induced hearing loss.

Supplementary Materials: Supplementary materials can be found at http://www.mdpi.com/1422-0067/ $17 / 3 / 301 /$ s1.

Acknowledgments: This work was supported by grants from the Key Project of National Natural Science Foundation of China (81230021), the Major State Basic Research Development Program of China (973 Program) (2011CB504504), International Science \& Technology Cooperation Program of China (2013DFE33160) and the National Nature Science Foundation of China (81000408, 81570923, 81470696, 81500793 and 81500795).

Author Contributions: Yu Sun, Wei-Jia Kong and $\mathrm{Xi}$ Lin conceived and designed the experiments; Xing-Xing Zhou, Sen Chen, Le Xie, Yu-Zi Ji and Qi Yang performed the experiments; Xing-Xing Zhou, Sen Chen and Yu Sun analyzed the data; Xing-Xing Zhou, Wen-Wen Wang, Jin-Tao Yu and Xia Wu contributed the mouse breeding; Sen Chen and Yu Sun wrote the paper.

\section{Abbreviations}

Cx26

NIHL

$\mathrm{KD}$

GJ

SNPs

$\mathrm{SPF}$

$\mathrm{KN}$

$\mathrm{HC}$

$\mathrm{OHC}$

\section{connexin26}

noise-induced hearing loss

knocked down

gap junction

single nucleotide polymorphisms

specific-pathogen free

knocked down + noise

hair cell

outer hair cell 
stria vascularis

TC tunnel of Corti

$\mathrm{MC}$ marginal cells

OC organ of Corti

BC basal cell

\section{References}

1. Elfgang, C.; Eckert, R.; Lichtenberg-Frate, H.; Butterweck, A.; Traub, O.; Klein, R.A.; Hulser, D.F.; Willecke, K. Specific permeability and selective formation of gap junction channels in connexin-transfected hela cells. J. Cell Biol. 1995, 129, 805-817. [CrossRef] [PubMed]

2. Zhao, H.B.; Yu, N.; Fleming, C.R. Gap junctional hemichannel-mediated atp release and hearing controls in the inner ear. Proc. Natl. Acad. Sci. USA 2005, 102, 18724-18729. [CrossRef] [PubMed]

3. Gossman, D.G.; Zhao, H.B. Hemichannel-mediated inositol 1,4,5-trisphosphate (IP3) release in the cochlea: A novel mechanism of IP3 intercellular signaling. Cell Commun. Adhes. 2008, 15, 305-315. [CrossRef] [PubMed]

4. Sun, J.; Ahmad, S.; Chen, S.; Tang, W.; Zhang, Y.; Chen, P.; Lin, X. Cochlear gap junctions coassembled from Cx26 and 30 show faster intercellular $\mathrm{Ca}^{2+}$ signaling than homomeric counterparts. Am. J. Physiol. Cell Physiol. 2005, 288, C613-C623. [CrossRef] [PubMed]

5. Kikuchi, T.; Kimura, R.S.; Paul, D.L.; Adams, J.C. Gap junctions in the rat cochlea: Immunohistochemical and ultrastructural analysis. Anat. Embryol. 1995, 191, 101-118. [CrossRef] [PubMed]

6. Iliades, T.; Eleftheriades, N.; Iliadou, V.; Pampanos, A.; Voyiatzis, N.; Economides, J.; Leotsakos, P.; Neou, P.; Tsakanikos, M.; Antoniadi, T.; et al. Prelingual nonsyndromic hearing loss in greece. Molecular and clinical findings. ORL J. Oto-Rhino-Laryngol. Relat. Spec. 2002, 64, 321-323. [CrossRef]

7. Zelante, L.; Gasparini, P.; Estivill, X.; Melchionda, S.; D'Agruma, L.; Govea, N.; Milá, M.; Monica, M.D.; Lutfi, J.; Shohat, M. Connexin 26 mutations associated with the most common form of non-syndromic neurosensory autosomal recessive deafness (DFNB1) in mediterraneans. Hum. Mol. Genet. 1997, 6, 1605-1609. [CrossRef] [PubMed]

8. Murgia, A.; Orzan, E.; Polli, R.; Martella, M.; Vinanzi, C.; Leonardi, E.; Arslan, E.; Zacchello, F. Cx26 deafness: Mutation analysis and clinical variability. J. Med. Genet. 1999, 36, 829-832. [PubMed]

9. Cohn, E.S.; Kelley, P.M.; Fowler, T.W.; Gorga, M.P.; Lefkowitz, D.M.; Kuehn, H.J.; Schaefer, G.B.; Gobar, L.S.; Hahn, F.J.; Harris, D.J.; et al. Clinical studies of families with hearing loss attributable to mutations in the connexin 26 gene (GJB2/DFNB1). Pediatrics 1999, 103, 546-550. [CrossRef] [PubMed]

10. Carlsson, P.-I.; Borg, E.; Grip, L.; Dahl, N.; Bondeson, M.-L. Variability in noise susceptibility in a swedish population: The role of 35delg mutation in the connexin 26 (GJB2) gene. Audiol. Med. 2004, 2, 123-130. [CrossRef]

11. Van Eyken, E.; van Laer, L.; Fransen, E.; Topsakal, V.; Hendrickx, J.-J.; Demeester, K.; van de Heyning, P.; Mäki-Torkko, E.; Hannula, S.; Sorri, M. The contribution of GJB2 (connexin 26) 35delg to age-related hearing impairment and noise-induced hearing loss. Otol. Neurotol. 2007, 28, 970-975. [PubMed]

12. Abreu-Silva, R.S.; Rincon, D.; Horimoto, A.R.; Sguillar, A.P.; Ricardo, L.A.; Kimura, L.; Batissoco, A.C.; Auricchio, M.T.; Otto, P.A.; Mingroni-Netto, R.C. The search of a genetic basis for noise-induced hearing loss (NIHL). Ann. Hum. Biol. 2011, 38, 210-218. [PubMed]

13. Pawelczyk, M.; van Laer, L.; Fransen, E.; Rajkowska, E.; Konings, A.; Carlsson, P.I.; Borg, E.; van Camp, G.; Sliwinska-Kowalska, M. Analysis of gene polymorphisms associated with $\mathrm{k}$ ion circulation in the inner ear of patients susceptible and resistant to noise-induced hearing loss. Ann. Hum. Genet. 2009, 73, 411-421. [PubMed]

14. Wang, S.L.; Yu, L.G.; Liu, R.P.; Zhu, W.Z.; Gao, W.M.; Xue, L.P.; Jiang, X.; Zhang, Y.H.; Yi, D.; Chen, D. Gene-gene interaction of GJB2, SOD2, and cat on occupational noise-induced hearing loss in chinese han population. Biomed. Environ. Sci.: BES 2014, 27, 965-968. [PubMed]

15. Inoshita, A.; Iizuka, T.; Okamura, H.O.; Minekawa, A.; Kojima, K.; Furukawa, M.; Kusunoki, T.; Ikeda, K. Postnatal development of the organ of corti in dominant-negative GJB2 transgenic mice. Neuroscience 2008, 156, 1039-1047. [PubMed] 
16. Cohen-Salmon, M.; Ott, T.; Michel, V.; Hardelin, J.P.; Perfettini, I.; Eybalin, M.; Wu, T.; Marcus, D.C.; Wangemann, P.; Willecke, K.; et al. Targeted ablation of connexin26 in the inner ear epithelial gap junction network causes hearing impairment and cell death. Curr. Biol.: CB 2002, 12, 1106-1111. [PubMed]

17. Wang, Y.; Chang, Q.; Tang, W.; Sun, Y.; Zhou, B.; Li, H.; Lin, X. Targeted connexin26 ablation arrests postnatal development of the organ of corti. Biochem. Biophys. Res. Commun. 2009, 385, 33-37. [CrossRef] [PubMed]

18. Chen, S.; Sun, Y.; Lin, X.; Kong, W. Down regulated connexin26 at different postnatal stage displayed different types of cellular degeneration and formation of organ of corti. Biochem. Biophys. Res. Commun. 2014, 445, 71-77. [CrossRef] [PubMed]

19. Chen, J.; Chen, J.; Zhu, Y.; Liang, C.; Zhao, H.-B. Deafness induced by connexin 26 (GJB2) deficiency is not determined by endocochlear potential $(\mathrm{EP})$ reduction but is associated with cochlear developmental disorders. Biochem. Biophys. Res. Commun. 2014, 448, 28-32. [CrossRef] [PubMed]

20. Zhu, Y.; Chen, J.; Liang, C.; Zong, L.; Jones, R.O.; Zhao, H.B. Connexin26 (GJB2) deficiency reduces active cochlear amplification leading to late-onset hearing loss. Neuroscience 2015, 284, 719-729. [CrossRef] [PubMed]

21. Chang, Q.; Tang, W.; Kim, Y.; Lin, X. Timed conditional null of connexin26 in mice reveals temporary requirements of connexin26 in key cochlear developmental events before the onset of hearing. Neurobiol. Dis. 2015, 73, 418-427. [CrossRef] [PubMed]

22. Lin, X.; Tang, W.; Ahmad, S.; Lu, J.; Colby, C.C.; Zhu, J.; Yu, Q. Applications of targeted gene capture and next-generation sequencing technologies in studies of human deafness and other genetic disabilities. Hear. Res. 2012, 288, 67-76. [CrossRef] [PubMed]

23. Sun, Y.; Tang, W.; Chang, Q.; Wang, Y.; Kong, W.; Lin, X. Connexin30 null and conditional connexin26 null mice display distinct pattern and time course of cellular degeneration in the cochlea. J. Comp. Neurol. 2009, 516, 569-579. [CrossRef] [PubMed]

24. Iizuka, T.; Kamiya, K.; Gotoh, S.; Sugitani, Y.; Suzuki, M.; Noda, T.; Minowa, O.; Ikeda, K. Perinatal GJB2 gene transfer rescues hearing in a mouse model of hereditary deafness. Hum. Mol. Genet. 2015, 24, 3651-3661. [CrossRef] [PubMed]

25. Beltramello, M.; Piazza, V.; Bukauskas, F.F.; Pozzan, T.; Mammano, F. Impaired permeability to ins $(1,4,5)$ P3 in a mutant connexin underlies recessive hereditary deafness. Nat. Cell Biol. 2005, 7, 63-69. [CrossRef] [PubMed]

26. Kelsell, D.P.; Dunlop, J.; Stevens, H.P.; Lench, N.J.; Liang, J.N.; Parry, G.; Mueller, R.F.; Leigh, I.M. Connexin 26 mutations in hereditary non-syndromic sensorineural deafness. Nature 1997, 387, 80-83. [CrossRef] [PubMed]

27. Pujol, R.; Lavigne-Rebillard, M.; Lenoir, M. Development of sensory and neural structures in the mammalian cochlea. In Development of the Auditory System; Springer: New York, NY, USA, 1998; pp. 146-192.

28. Liang, C.; Zhu, Y.; Zong, L.; Lu, G.-J.; Zhao, H.-B. Cell degeneration is not a primary causer for connexin26 (GJB2) deficiency associated hearing loss. Neurosci. Lett. 2012, 528, 36-41. [CrossRef] [PubMed]

29. Zhu, Y.; Liang, C.; Chen, J.; Zong, L.; Chen, G.D.; Zhao, H.B. Active cochlear amplification is dependent on supporting cell gap junctions. Nat. Commun. 2013, 4, 1786. [CrossRef] [PubMed]

30. Wang, Y.; Hirose, K.; Liberman, M.C. Dynamics of noise-induced cellular injury and repair in the mouse cochlea. J. Assoc. Res. Otolaryngol. 2002, 3, 248-268. [CrossRef] [PubMed]

31. Konings, A.; van Laer, L.; van Camp, G. Genetic studies on noise-induced hearing loss: A review. Ear Hear. 2009, 30, 151-159. [CrossRef] [PubMed]

32. Vicente-Torres, M.A.; Schacht, J. A bad link to mitochondrial cell death in the cochlea of mice with noise-induced hearing loss. J. Neurosci. Res. 2006, 83, 1564-1572. [CrossRef] [PubMed]

33. Chen, G.-D.; Fechter, L.D. The relationship between noise-induced hearing loss and hair cell loss in rats. Hear. Res. 2003, 177, 81-90. [CrossRef]

34. Yu, J.; Wang, Y.; Liu, P.; Li, Q.; Sun, Y.; Kong, W. Mitochondrial DNA common deletion increases susceptibility to noise-induced hearing loss in a mimetic aging rat model. Biochem. Biophys. Res. Commun. 2014, 453, 515-520. [CrossRef] [PubMed]

35. Zilberstein, Y.; Liberman, M.C.; Corfas, G. Inner hair cells are not required for survival of spiral ganglion neurons in the adult cochlea. J. Neurosci. 2012, 32, 405-410. [CrossRef] [PubMed]

36. Lin, L.; Wang, Y.F.; Wang, S.Y.; Liu, S.F.; Yu, Z.; Xi, L.; Li, H.W. Ultrastructural pathological changes in the cochlear cells of connexin 26 conditional knockout mice. Mol. Med. Rep. 2013, 8, 1029-1036. [PubMed] 
37. Suzuki, T.; Matsunami, T.; Hisa, Y.; Takata, K.; Takamatsu, T.; Oyamada, M. Roles of gap junctions in glucose transport from glucose transporter 1-positive to -negative cells in the lateral wall of the rat cochlea. Histochem. Cell Biol. 2009, 131, 89-102. [CrossRef] [PubMed]

38. Matsunami, T.; Suzuki, T.; Hisa, Y.; Takata, K.; Takamatsu, T.; Oyamada, M. Gap junctions mediate glucose transport between GLUT1-positive and-negative cells in the spiral limbus of the rat cochlea. Cell. Commun. Adhes. 2006, 13, 93-102. [CrossRef] [PubMed]

39. Chang, Q.; Tang, W.; Ahmad, S.; Zhou, B.; Lin, X. Gap junction mediated intercellular metabolite transfer in the cochlea is compromised in connexin30 null mice. PLoS ONE 2008, 3, e4088. [CrossRef] [PubMed]

40. Chen, F.-Q.; Zheng, H.-W.; Hill, K.; Sha, S.-H. Traumatic noise activates Rho-family Gtpases through transient cellular energy depletion. J. Neurosci. 2012, 32, 12421-12430. [CrossRef] [PubMed]

41. Nagashima, R.; Yamaguchi, T.; Kuramoto, N.; Ogita, K. Acoustic overstimulation activates 5'-AMP-activated protein kinase through a temporary decrease in ATP level in the cochlear spiral ligament prior to permanent hearing loss in mice. Neurochem. Int. 2011, 59, 812-820. [CrossRef] [PubMed]

42. Yamane, H.; Nakai, Y.; Takayama, M.; Konishi, K.; Iguchi, H.; Nakagawa, T.; Shibata, S.; Kato, A.; Sunami, K.; Kawakatsu, C. The emergence of free radicals after acoustic trauma and strial blood flow. Acta Oto-Laryngol. Suppl. 1995, 519, 87-92. [CrossRef]

43. Ohlemiller, K.K.; Wright, J.S.; Dugan, L.L. Early elevation of cochlear reactive oxygen species following noise exposure. Audiol. Neuro-Otol. 1999, 4, 229-236. [CrossRef]

44. Feine, I.; Pinkas, I.; Salomon, Y.; Scherz, A. Local oxidative stress expansion through endothelial cells-A key role for gap junction intercellular communication. PLoS ONE 2012, 7, e41633. [CrossRef] [PubMed]

45. Le, H.T.; Sin, W.C.; Lozinsky, S.; Bechberger, J.; Vega, J.L.; Guo, X.Q.; Saez, J.C.; Naus, C.C. Gap junction intercellular communication mediated by connexin 43 in astrocytes is essential for their resistance to oxidative stress. J. Biol. Chem. 2014, 289, 1345-1354. [CrossRef] [PubMed]

(C) 2016 by the authors; licensee MDPI, Basel, Switzerland. This article is an open access article distributed under the terms and conditions of the Creative Commons by Attribution (CC-BY) license (http://creativecommons.org/licenses/by/4.0/). 